\title{
Real-Time Geospatial Data Collection and Visualization with Smartphone
}

\author{
Koko Lwin, Misao Hashimoto, Yuji Murayama \\ Division of Spatial Information Science, Faculty of Life and Environmental Sciences, University of Tsukuba, \\ Tsukuba, Japan \\ Email: kokolwin@live.com
}

Received 5 February 2014; revised 5 March 2014; accepted 12 March 2014

Copyright (C) 2014 by authors and Scientific Research Publishing Inc.

This work is licensed under the Creative Commons Attribution International License (CC BY). http://creativecommons.org/licenses/by/4.0/

(c) (i) Open Access

\begin{abstract}
The development of the Global Navigation System and wireless networking technologies have changed the way we live, communicate, share information and even the collection of geospatial data in the field. Along with wireless networking technologies, the improvement in computational power of handheld devices such as smartphones, tablet PCs, ultra-mobile personal computers (UMPCs) and netbook computers allow field users to connect, store and stream large amounts of geospatial data from the web-server. Nowadays, geospatial data collection is more flexible and timely manner. In this paper we discuss field data collection using a smartphone and web-based GIS system, which collects, integrates, visualizes and analyzes the collected data in real-time. We built a web-GIS system for creating a user account, acquiring coordinates from GPS embedded devices or wireless access points, and providing a user-friendly survey form. The collected data can be visualized and analyzed by performing thematic mapping, labeling, symbolizing, querying and generating a summary report. We tested this system on a university campus management system, in which we collected information on illegal disposal sites and parking events within the university campus.
\end{abstract}

\section{Keywords}

Web-GIS, Smartphone, Smart Data Collection, Visualization

\section{Introduction}

Over the decades ago, field data collection (i.e. pen-and-paper based) is an expensive, time consuming and cumbersome task. For example, basemaps need to be prepared, an ancillary dataset collected, as well as other paperwork. We need to take all the material to the field, and this is not practical in real-time disaster information 
collection, which occurs in unpredictable places and requires a quick emergency response. The combination of mobile communication technologies and Wi-Fi-based positioning system allow field users to acquire location information in timely and handy manner. Moreover, under the client-server setting in field data collection, a field user may take advantage of the digital repositories prepared for data collection (i.e. basemaps, satellite images and other ancillary data), as well as information resources more generally available via the Web [1].

The harmonization between wireless networking and Web-GIS/Web services allows mobile GIS users to stream large amounts of geo-information as a basemap, which dramatically eliminates cost and data processing times for field data collection. On the other hand, due to the popularity of social networking and location-based services with mobile devices, public participation in geospatial data collection is now becoming more and more import in decision making processes. For example, finding greenness route path on smartphone [2], the concepts of the Spatially Integrated Online Social Survey System (SIOSS) [3] and the future of citizen science [4] will empower citizens to participate in government decision-making processes under the framework of PPGIS (Public Participation GIS).

Previously we have tested the practical use of mobile communicational devices for geospatial data collection, such as personal mobile phones used in field data collection through the POP3 mail server [5]. This system is convenient and cost effective. Furthermore, the availability of built-in GPS in mobile phone and the development of locational services based on the wireless networking environment, means that nowadays field data collection is more accurate than ever before, and getting locations from the field is no longer critical work. In this paper, we built a Web-based GIS system to provide geographical positions in the field and an interactive field survey form for multiple users, by providing rich Graphical User Interfaces (GUIs). Moreover, this Web-based GIS system will collect, integrate, retrieve, visualize and analyze the collected data on a real-time basis.

This system has been used for a university campus information and management system in order to improve the daily life and administrative work of students. The main objective of this project is to demonstrate real-time geospatial data collection and the understanding of the common GIS functions to the students. This real-time geospatial data collection under a wireless networking environment method has been tested by the students of the University of Tsukuba, Japan, during their field survey course, which is part of the university's Campus GIS project. Under the Campus GIS project, individual students are required to collect and report illegal bike or motorbike parking, illegal waste disposal site locations, and footprints caused by people walking on the grass or who walk between trees instead of using the authorized paths (See the results at:

http://land.geo.tsukuba.ac.jp/campusgis). Later, this information is used by the university administrators to maintain the campus landscape and manage the student facilities.

\section{Positioning in Field Data Collection}

Recently, the use of mobile communication devices, such as smartphones and cellular phones, is increasing in field data collection due to the emergence of embedded GPS and wireless networking technologies. Obtaining the location information in the field is the first task in geospatial data collection. There are several ways to get the coordinate information from the field. Moreover, some Web and mobile applications can estimate your location in order to provide you with a more useful service. Every day millions of people around the world use location-based services with mobile devices. Under the Wi-Fi networking environment, the estimating of the location can be done in several different ways. Because GPS is not always available and locations derived from cell towers are not very accurate, Google (and other Internet companies) use publicly broadcast Wi-Fi data from wireless access points to improve the location-based services. By using signals from these access points, the program can read the position of devices and locate the user on a map. However, the accuracy of positions using wireless environment can vary several meters. Therefore, to correct these errors or locate the accurate positions, Web-based high spatial resolution satellite image was used. By providing a tool "Read the Coordinates from a Map” (Figure 3, Item 4) can locate accurate position based on building foot print shape and clear surrounding landscape patterns. Table 1 summarizes coordinate acquisition methods and their advantages and disadvantages for various applications.

\section{Real-Time Geospatial Data Collection}

Real-time geospatial data collection is important in weather information collection, hydrological monitoring systems, post disaster assessment and traffic flow monitoring systems. Recently, some studies used smartphone 
Table 1. Coordinate acquisition methods and their advantages and disadvantages for various applications.

\begin{tabular}{|c|c|c|}
\hline Method & Advantages & Disadvantages \\
\hline Handheld GPS & $\begin{array}{l}\text { Good for rural areas where open spaces are abundant } \\
\text { while landmarks are absent, such as road intersections, } \\
\text { building shapes, etc. } \\
\text { Small and handy } \\
\text { Provide software to integrate with other computational } \\
\text { devices (e.g. notebook, netbook, etc.) } \\
\text { Good for geologists, archaeologists, ecologists, etc. }\end{array}$ & $\begin{array}{l}\text { Landscape dependent, accuracy varies on the } \\
\text { type of landscape such as open space or } \\
\text { semi-open space or closed space and availability } \\
\text { of WAAS Wide Area Augmentation System. }\end{array}$ \\
\hline $\begin{array}{l}\text { Built-in GPS or } \\
\text { wireless access point }\end{array}$ & $\begin{array}{l}\text { Good for urban area studies where wireless access is } \\
\text { available } \\
\text { Easy to read coordinates from built-in GPS devices or } \\
\text { Wi-Fi-based positioning systems }\end{array}$ & $\begin{array}{l}\text { Requires wireless networking infrastructure } \\
\text { Costly (i.e. smartphone and tablet PC) } \\
\text { Accuracy can vary } 10 \text { to } 20 \mathrm{~m}\end{array}$ \\
\hline $\begin{array}{l}\text { Basemap with high } \\
\text { resolution satellite images } \\
\text { (<1 m spatial resolution) }\end{array}$ & $\begin{array}{l}\text { Good for urban area studies where the landmarks are } \\
\text { abundant (road intersections, building shapes, } \\
\text { traffic signs, etc.) } \\
\text { Landscape independent } \\
\text { Much accurate than other methods }\end{array}$ & $\begin{array}{l}\text { Requires prior knowledge of that area } \\
\text { Requires software to use } \\
\text { Costly for purchasing data, processing } \\
\text { time and storage device }\end{array}$ \\
\hline $\begin{array}{l}\text { Geocoding and } \\
\text { address matching }\end{array}$ & $\begin{array}{l}\text { Good for large amounts of data conversion, such as } \\
\text { patient address, customer address, etc. } \\
\text { Timely manner } \\
\text { Good for finding spatial relationships between } \\
\text { humans and the environment, health, disease } \\
\text { dispersion, etc. }\end{array}$ & $\begin{array}{l}\text { Requires national scale geodatabase, such as } \\
\text { the National Spatial Data Infrastructure (NSDI) } \\
\text { Accuracy depends on dataset available, such as } \\
\text { the level of the street or parcel unit } \\
\text { Not applicable for developing countries where } \\
\text { fine scale GIS data are absent }\end{array}$ \\
\hline
\end{tabular}

Table modified from: Lwin et al, 2012 [6]. * If the GIS application can be integrated with Google Maps or Microsoft Bing Maps through the Web map service (WMS) in an application these disadvantages can be ignored. For example, Google WMS is a WMS interface for Google Maps, which allows users to access Google Map data from GIS applications via a HTTP interface. It can provide Google Map image data to any GIS application that can use a WMS service for raster data.

to collect earthquake disaster area information [7], driving information [8] and educational administration inquire system [9]. Moreover, building the centralized GIS database for real-time geospatial data collecting, integrating and visualization is important for effective decision making to multiple spatial information users. We collected the locations of illegal disposal sites and parking places within the university campus. The disposal material types include burnable and unburnable, and the parking types include bicycle, motorbike and car. A field survey was carried out with a smartphone and tablet PC. Figure 1 shows the overview of real-time geospatial data collection, processing and analysis within the wireless networking environment. This system required to use Smartphone or tablet PC with wireless networking capabilities. Figure 2 shows the Wi-Fi Internet access points inside the university campus. Figure 3 shows the Web-based GUI of a real-time geospatial data collection program for mobile users. Users are required to create their own account before surveying, and they can only view and edit their own data.

We constructed a Web-GIS application which plays a central role in creating the survey user's account, providing a survey form, basemap, and reading coordinates from a built-in GPS device or wireless access point, manages survey items and attaches images to the record (Figure 4). This is ideal for real-time field data collection with multiple users for use in a timely and convenient manner. A pre-designed survey form helps multiple users to input attribute values by selecting the appropriate items in dropdown list boxes. In this application we collected information on illegal disposal sites and parking activities within the university campus for the purpose of campus management. Users can also edit the records with update and delete functions (Figure 5), and are able to see the information other people are collecting on the main webpage. All data collected from multiple users are recorded instantly and are ready for visualization and analysis. The system is reusable for various field data collection by changing the survey form.

The overall system is built on Microsoft ASP.NET with an AJAX Extension and VDS Technologies (Web Mapping Components for ASP.NET). ASP.NET is a web application framework marketed by Microsoft that programmers can use to build dynamic websites, web applications and XML web services. AspMap for .NET from VDS Technologies is a set of high-performance web-mapping components and controls for embedding maps in ASP.NET applications (Web Forms). 


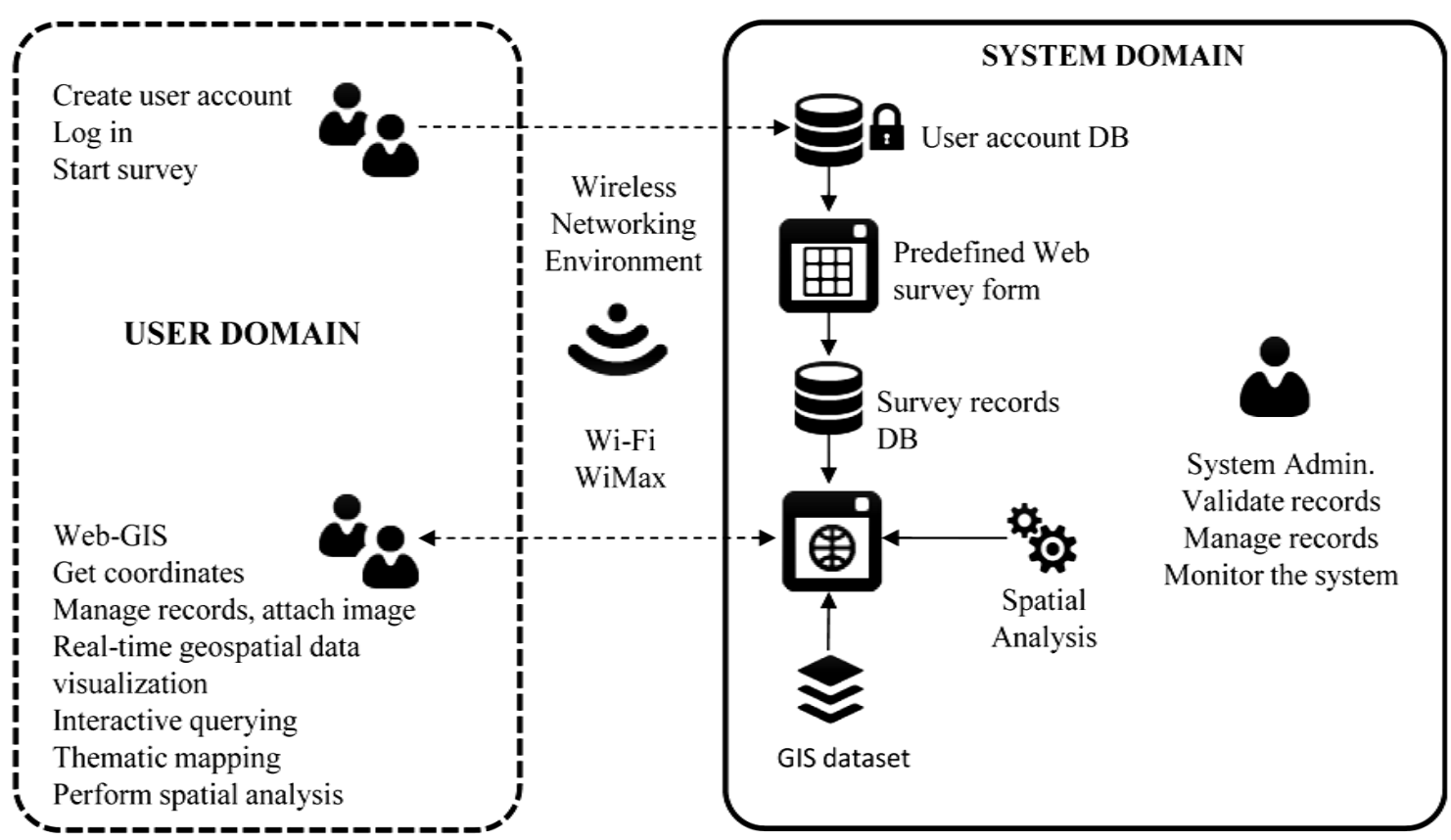

Figure 1. Overview of real-time geospatial data collection, processing and analysis within a wireless networking environment.

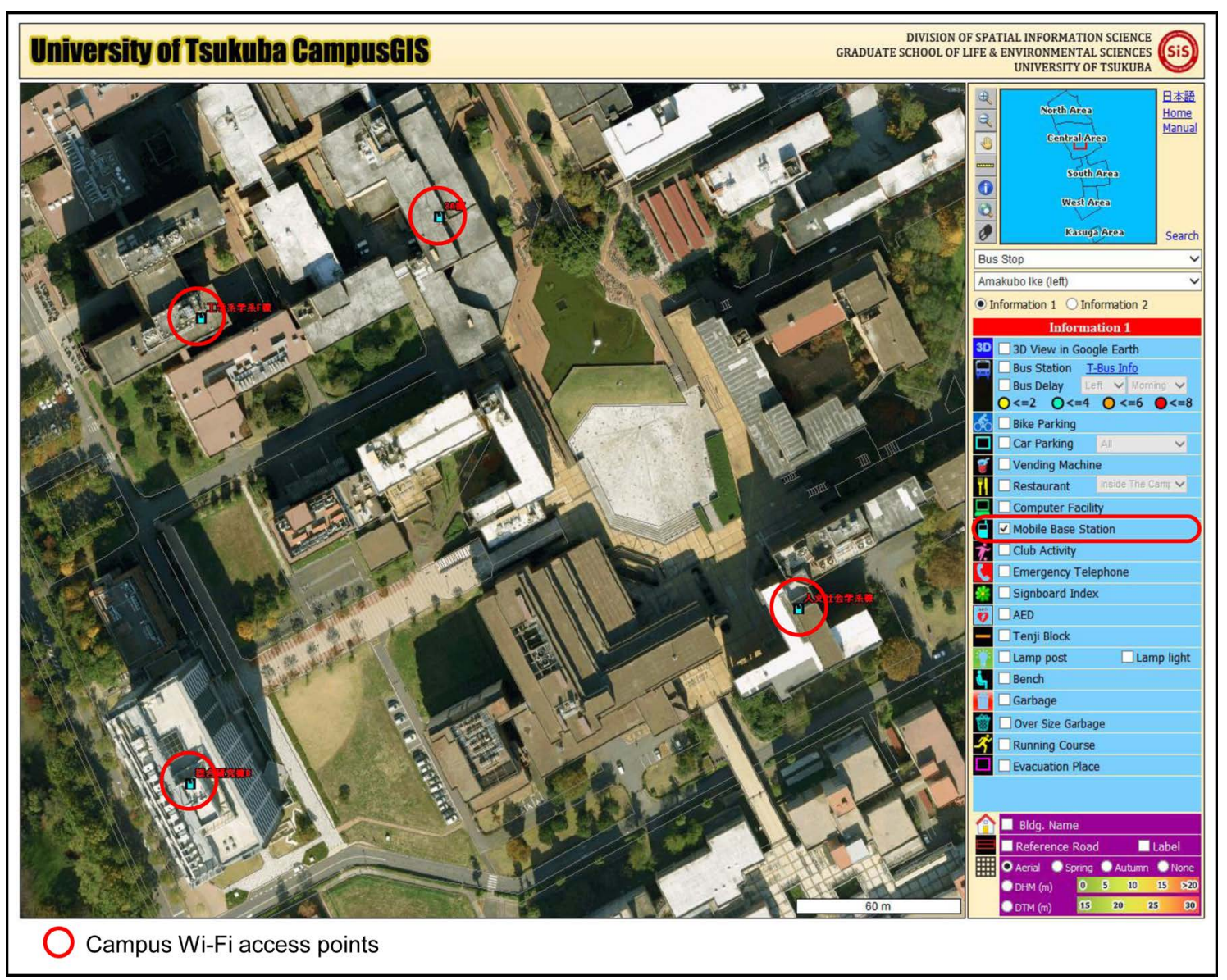

Figure 2. Campus Wi-Fi Internet access points (students can use either Smartphone or tablet PC inside the campus). 


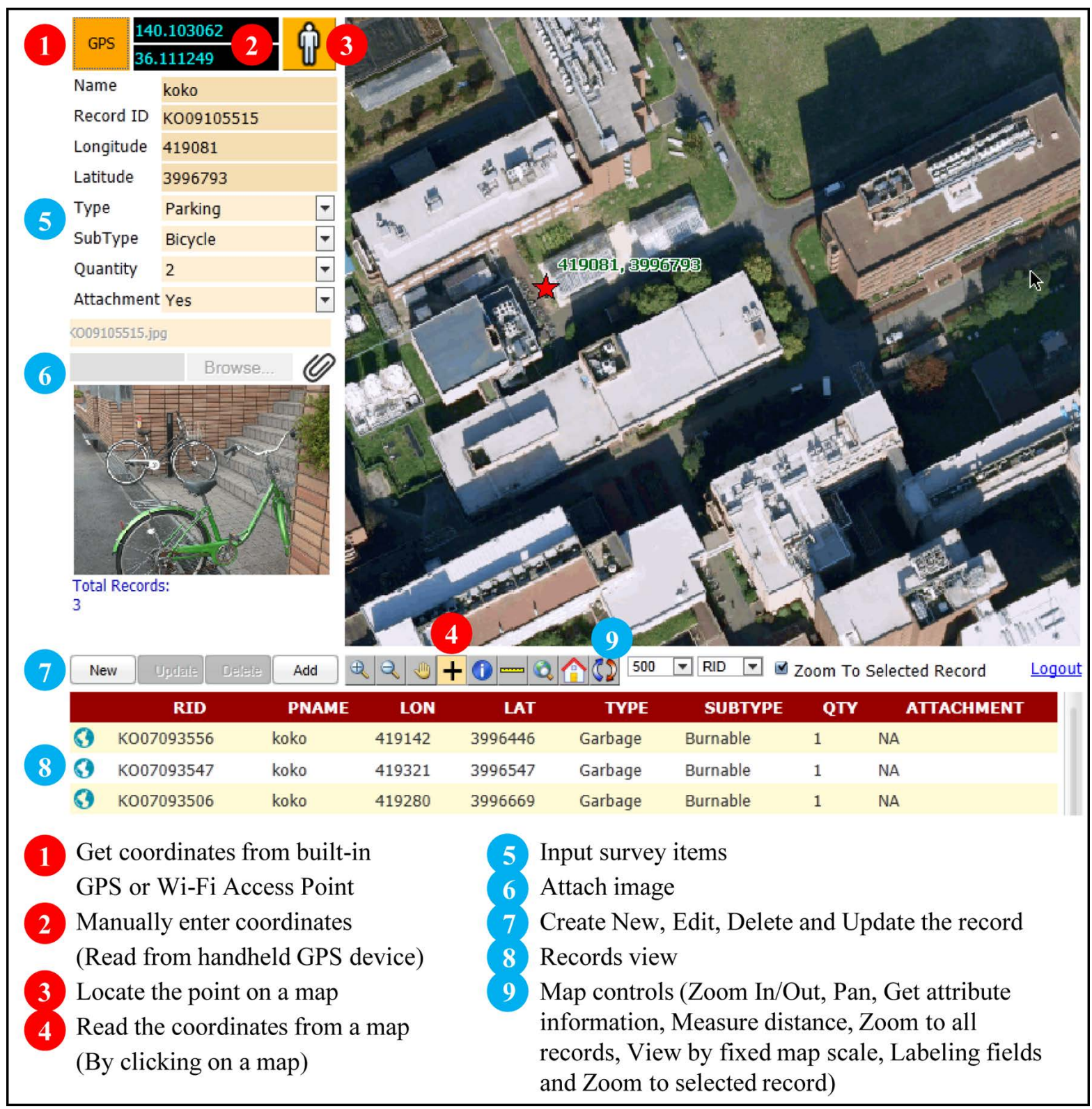

Figure 3. GUI overview of real-time geospatial data collection program.

\section{Real-Time Geospatial Data Processing and Analysis}

The centralized Web-GIS collects, stores, integrates and processes the common GIS functions, such as summarizing the collected points by administration zones for thematic mapping, and building a database for further querying. The Web-GIS also provides some spatial analysis functions, such as finding attributes inside the user-defined area in order to analyze what kinds of activities are abundant in nearby or specific buildings.

\subsection{Generating Summary Report}

Users can generate a summary report of up-to-date field data (Figure 6), which will be shown as text.

\subsection{Labeling, Symbolizing and Thematic Mapping}

Web-GIS also offers common cartographic functions, such as labeling and symbolizing of the features and 


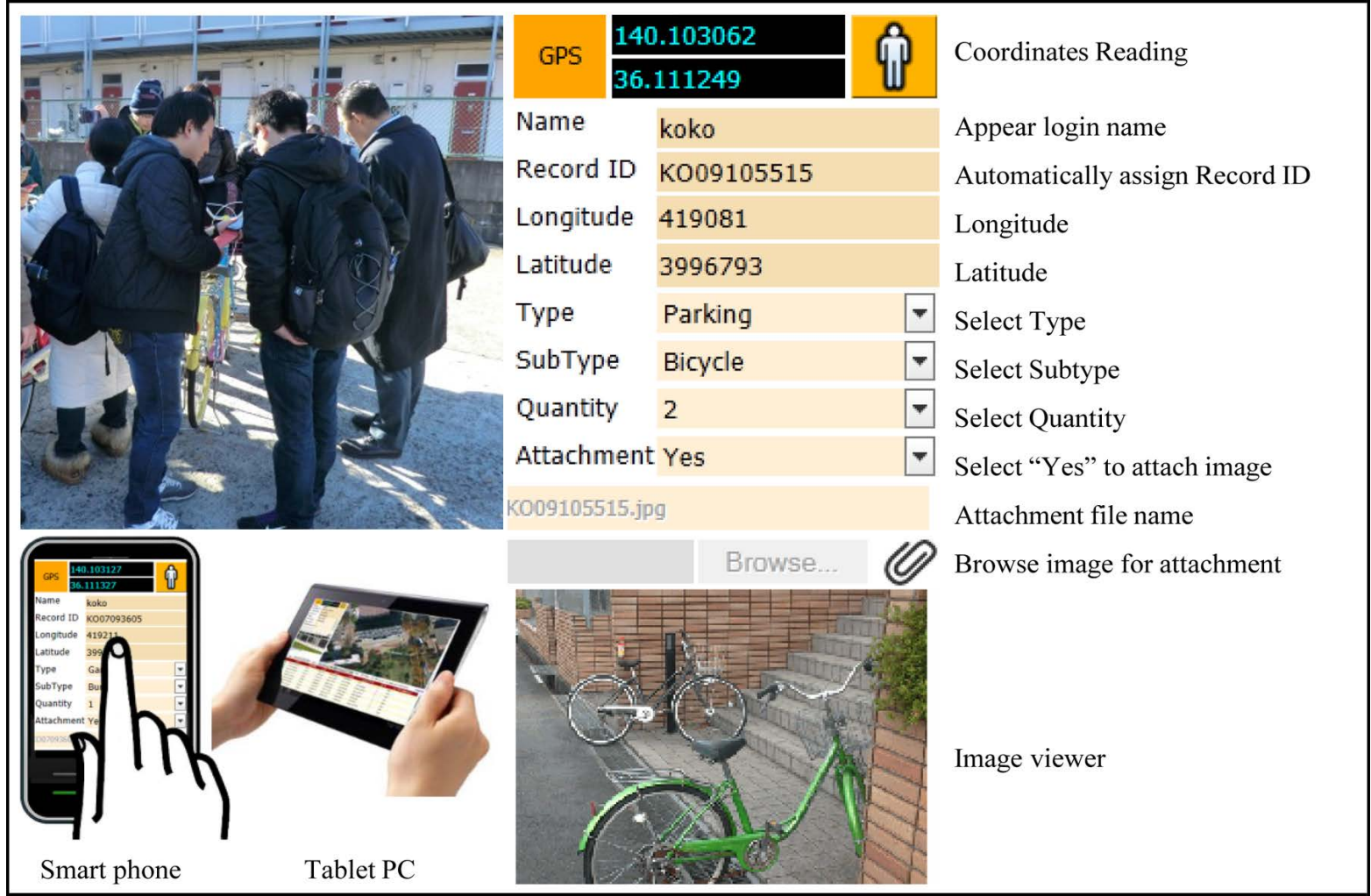

Figure 4. Functional details of data entry form.

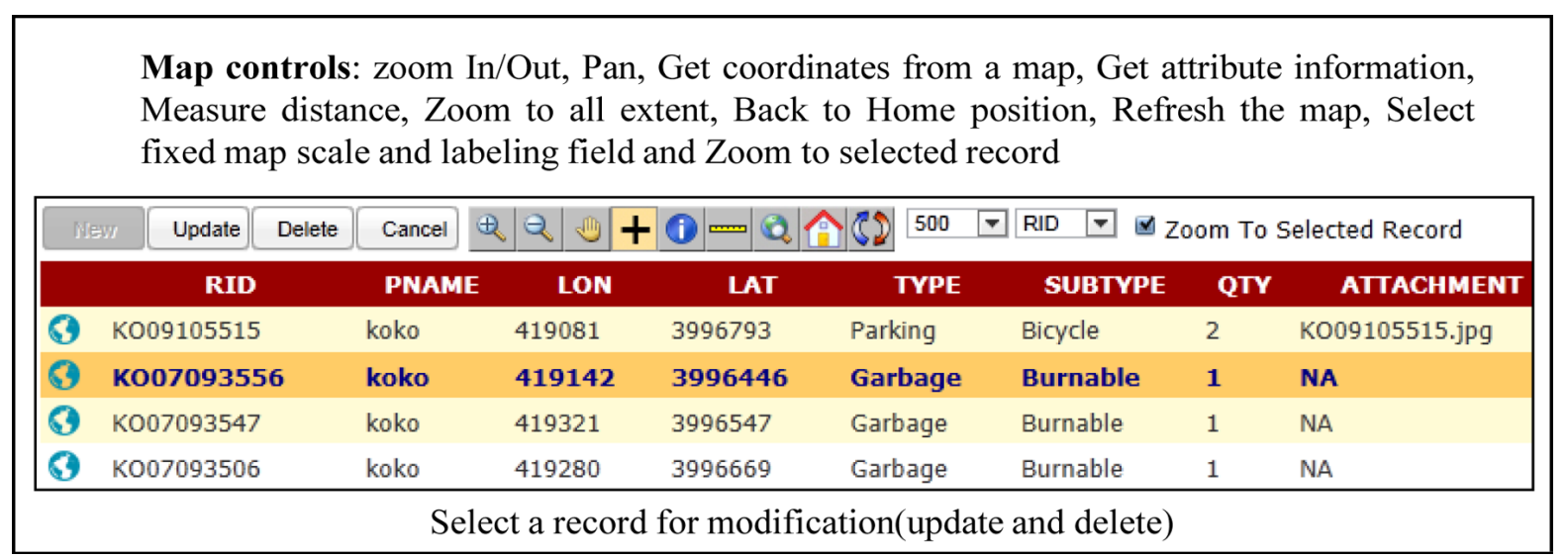

Figure 5. Functional details of record management.

thematic mapping of the field survey data by administrative zones. Due to increasing power of computational devices and smaller form of personal computers, real-time digital mapping and cartography is possible to mobile GIS users (Cartography in a mobile internet age) which deliver the maps and multimedia on World Wide Web [10] [11]. Figure 7 shows the labeling and symbolization of features, and Figure 8 shows real-time thematic mapping by user-defined attributes. From the map, it can be seen that illegal parking activities are dominant in the central areas where the research centers and administration offices are located, and illegal disposal events are more dominant around the edge of the campus where the housing and dormitories are located.

\subsection{Labeling, Symbolizing and Thematic Mapping}

By providing a “Query Builder”, users can search based on various query strings. The Web-GIS also provides a 


\begin{tabular}{|c|c|}
\hline REPORT OF FIELD DATA & SUMMARY BY ADMINISTRATION ZONES \\
\hline DATE: 2/5/2013 11:52:22 AM & Total Records By Zones \\
\hline & $5 \quad$ Hirasuna Residence Area \\
\hline SUMMARY BY ITEMS & 46 Art and Physical Education Area \\
\hline----- & 11 Agri. and Fores. Research Center Area \\
\hline TOTAL RECORDS: 241 & 16 Administration Center Area \\
\hline 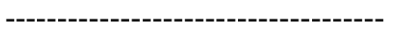 & 37 Research Center Area \\
\hline Sum of Garbage: 144 (33) & 17 Area 3 \\
\hline$---\cdot$ & 19 Area 2 \\
\hline Burnable: 32 (23) & 48 Area 1 \\
\hline Unburnable: $112(10)$ & 22 University Hall \\
\hline--- & 16 Medical Area \\
\hline Sum of Parking: 2907 (208) & 3 Okoshi Residence Area \\
\hline Bicycle: $1720(101)$ & Garbage By Zones \\
\hline Motorbike: $112(33)$ & 21 Hirasuna Residence Area \\
\hline \multirow[t]{2}{*}{ Car: $1075(74)$} & 14 Agri. and Fores. Research Center Area \\
\hline & 7 Administration Center Area \\
\hline
\end{tabular}

Figure 6. Generating a summary report of field survey data.

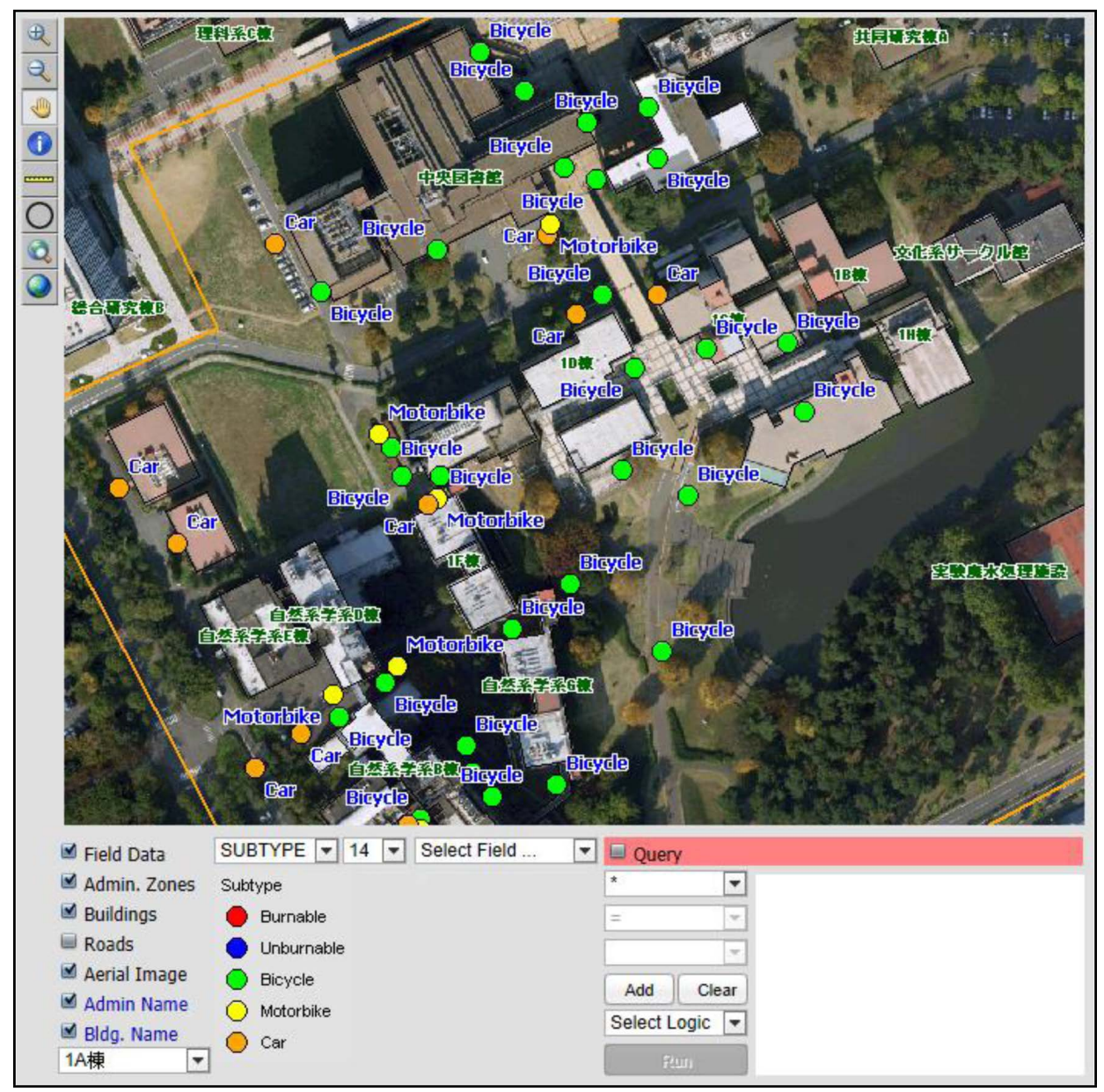

Figure 7. Labeling and symbolizing by subtype attribute field. 
spatial query process, such as what kinds of event are dominant $500 \mathrm{~m}$ from a specific department or office. Figure 9 shows the query process, and Figure 10 shows a search by a user-defined distance. The number in a bracket is number of points (locations) and the number in no bracket is number of items (quantity), for example, 95 (9) means total 95 cars are illegally parking at 9 locations. In a map we can see only one point, but if we click on a point, the amount of items will be displayed. We can also coloring (Thematic Mapping) by this amount, so the administrators can see not only location, but also the amount of items. This is especially for illegal parking activities.

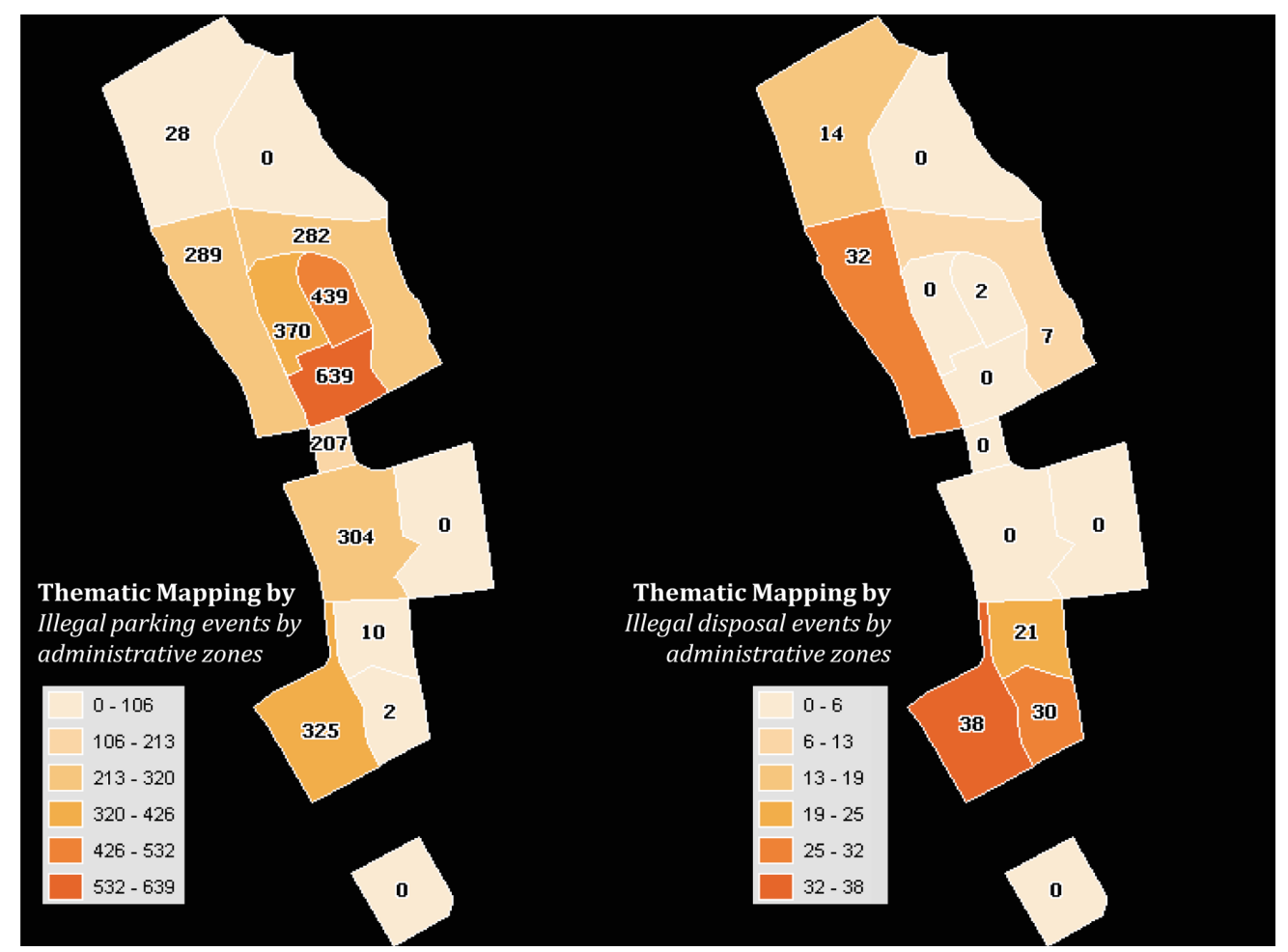

Figure 8. Thematic mapping by user-defined attributes.

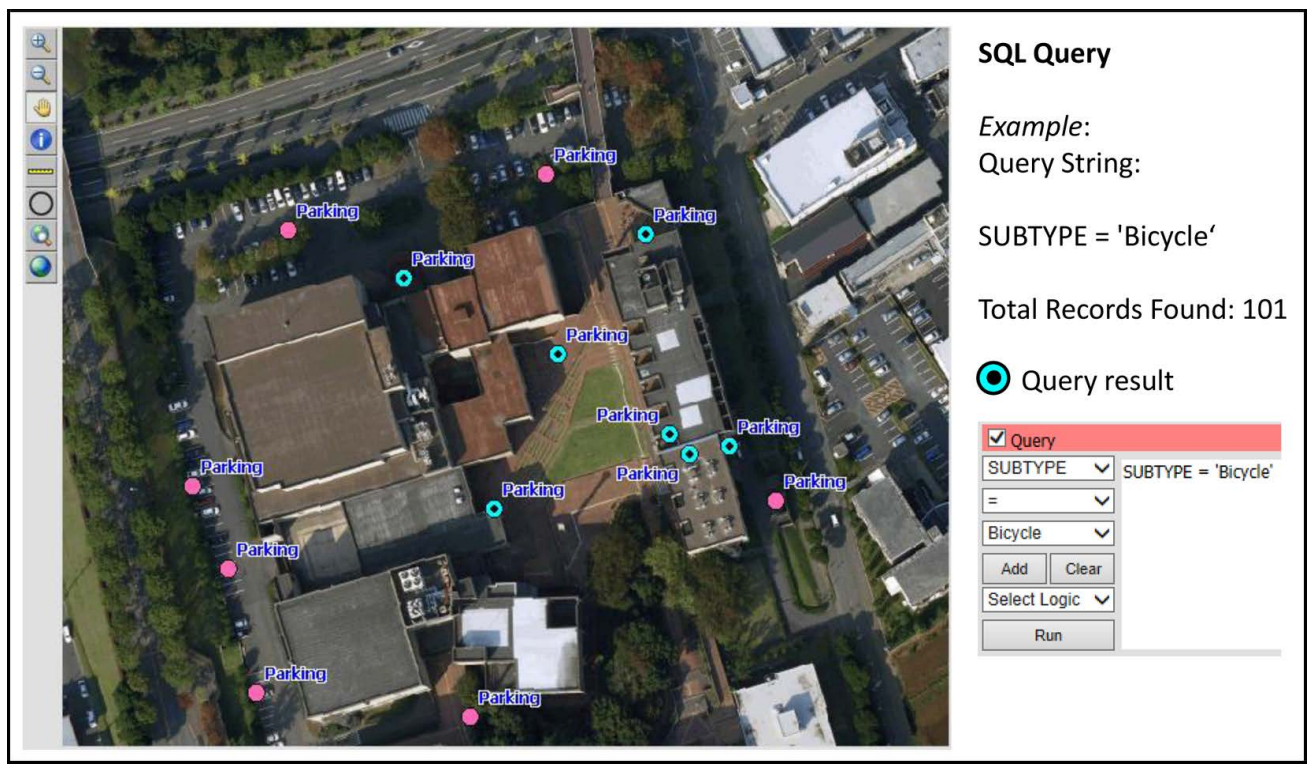

Figure 9. Performing query process by applying various query strings. 


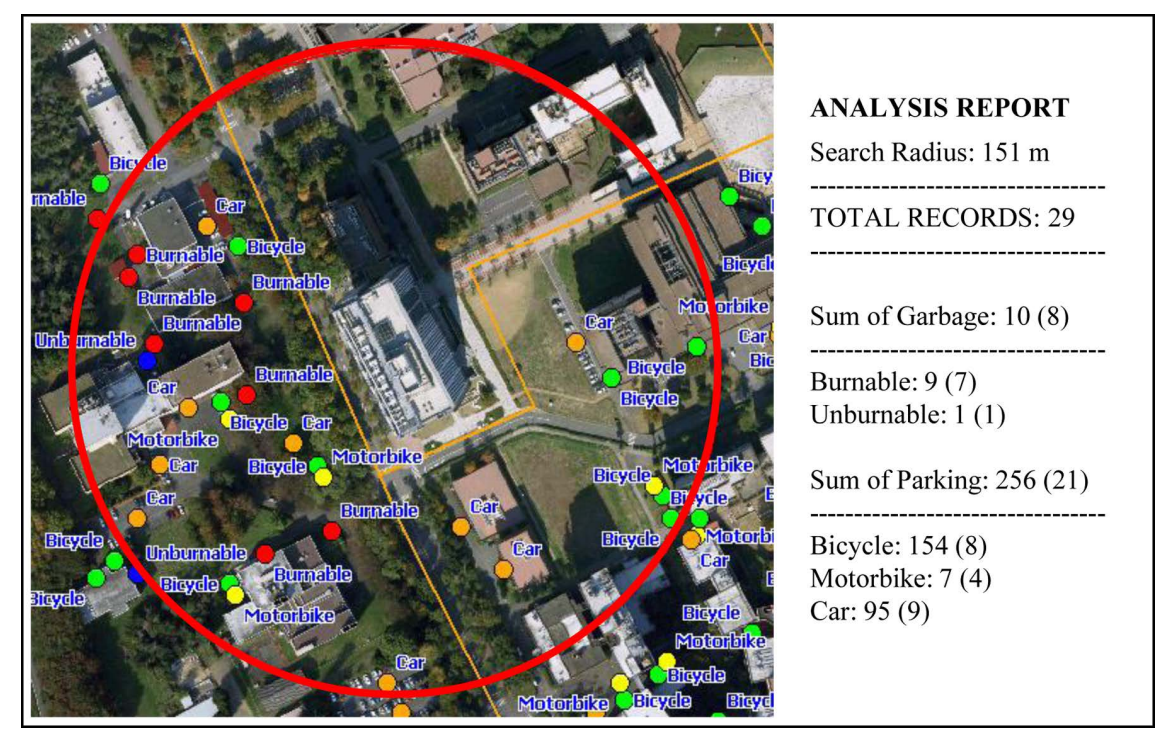

Figure 10. Query by user-defined distance from specific building.

\section{Conclusion}

The use of mobile communication devices, such as smartphones and cellular phones, for field data collection is increasing due to the emergence of embedded Global Positioning Systems (GPS) and wireless Internet access. Accurate, timely and convenient field data collection is required for disaster management and a quick response during emergencies. In this project, the utilization of wireless Internet access and smartphones in field data collection is handy and timely manner. Moreover, the construction of Web-GIS provides a pre-defined userfriendly Web-based survey form and coordinate information from mobile devices, which dramatically improved the finding of locations and entering of data during the field work. The Web-GIS also collects, integrates and processes all field data entered, which eliminates data handling tasks after the field survey. Due to the real-time information approach, the results can be viewed, queried and analyzed instantly, based on up-to-date information. This is ideal for use in disaster and emergency response systems and in meteorological data collection. The system itself is reusable and updatable for various field data collection purposes.

\section{Acknowledgements}

This research is supported by the Data Bank Project, University of Tsukuba (Chief investigator: Kazuo Kishimoto) and the Japan Society for the Promotion of Science and Technology (JSPS) under the "Grant-in-Aid for Scientific Research A" projects of "Systematization of fieldwork methodology: A study on capture, management, analysis and circulation of geographical data” (Chief investigator: Yuji Murayama).

\section{References}

[1] Nusser, S.M., Miller, L.L., Clarke, K. and Goodchild, M.F. (2001) Future Views of Field Data Collection in Statistical Surveys. Proceedings of Digital Government Dot Org 2001 National Conference on Digital Government Research, LA.

[2] Lwin, K.K. and Murayama. Y. (2013) Smart Eco-Path Finder for Mobile GIS Users. URISA Journal (Urban and Regional Information System), 25, 5-13.

http://www.urisa.org/clientuploads/directory/Documents/Journal/Vol25No2_onlinefinal.pdf

[3] Lwin, K.K. and Murayama, Y.A. (2008) Construction of Test Bed for Spatially1 Integrated Online Social Survey System (SIOSSS). URISA's 2008 Annual Conference \& Exposition, New Orleans. http://training.esri.com/bibliography/index.cfm?event=general.RecordDetail\&ID=132398

[4] Newman, G., Wiggins, A., Crall, A., Graham, E., Newman, S. and Crowston, K. (2012) The Future of Citizen Science: Emerging Technologies and Shifting Paradigms. Frontiers in Ecology and the Environment, 10, 298-304. http://dx.doi.org/10.1890/110294 
[5] Lwin, K.K. and Murayama, Y. (2011) Web-Based GIS System for Real-Time Field Data Collection Using a Personal Mobile Phone. Journal of Geographic Information Systems, 3, 382-389. http://dx.doi.org/10.4236/jgis.2011.34037

[6] Lwin, K.K., Estoque, R.C. and Murayama, Y. (2012) Data Collection, Processing and Applications for Geospatial Analysis. In: Murayama, Y., Ed., Progress in Geospatial Analysis, Springer, Tokyo. http://dx.doi.org/10.1007/978-4-431-54000-7_33

[7] Shan, W., Feng, J., Chang, J., Yang, F. and Li, Z. (2012) Collecting Earthquake Disaster Area Information Using Smart Phone. International Conference on System Science and Engineering (ICSSE), 30 June-2 July 2012, 310-314.

[8] Kim, M., Kim, M.J., Jang, J., Jeong, D.W., Baek, S.H. and Song, M.S. (2012) Design of Smart Driving Information Check System Using Smart Phone and Wireless Personal Area Network. 4th International Conference on Ubiquitous and Future Networks (ICUFN), 4-6 July 2012, 389-393.

[9] Shan, W., Wang, M., Feng, J. and Li, Z. (2012) A Study on Educational Administration Inquire System Based on Mobile Device. IEEE International Conference on Computer Science and Automation Engineering (CSAE), 3, 392-395.

[10] Clarke, K.C. (2001) Cartography in a Mobile Internet Age. Proceedings of the 20th International Cartographic Conference, Beijing, 6-10 August 2001, 1481-1488.

[11] Cartwright, W.E. (1997) New Media and Its Application to the Production of Map Products. Computers and Geosciences, 23, 447-456. http://dx.doi.org/10.1016/S0098-3004(97)00008-3 